\title{
Review XII.
}

1. A Treatise on the Continued Fevers of Great Britain. By Charles Murchison, M.D., \&c.-London, 1862. pp. 638.

2. Lectures on the Distinctive Characters, Pathology, and Treatment of Continued Fevers, delivered at the Royal College of Physicians of London. By Alexander Tweedie, M.D., F.R.S.-London, 1862. pp. 301.

3. Ten Lectures Introductory to the Study of Fever. By ANDREW Anderson, M.D., Lecturer on the Practice of Medicine in Anderson's University, Glasgow.-London, 1861. pp. 180.

4. Typhoüd Fever in India: its Clinical Characters, Morbid Anatomy, and Etiological Relations. By W. Hanbury, Surgeon 33rd Foot. (Trans. Medical and Physical Society of Bombay, No. 7, New Series.)-Bombay, 1861.

5. Further Observations on Typhus and Typhoïd Fevers, as seen in Dublin; especially the United Form they assumed during the first half of the year 1862. By Henry KenNedy, A.B., M.B.Dublin, 1862. pp. 28.

6. Remarks on the Changes which are supposed to have taken place in the Type of Continued Fever. By Charles Murchison, M.D. (From the 'Edinburgh Medical Journal,' August, 1858.) pp. 6.

7. Syllabus of the Lectures on the Causes of Fevers, delivered during the Session 1860-61. With an Etiological Nosology. By Tномаs LAYCOCK, M.D., F.R.S.E., \&c. \&c.-Edinburgh, 1861. pp. 19.

8. On Malaria and Miasmata, and their Influence in the Production of Typhus and Typhoïd Fevers, Cholera, and the Exanthemata. By Thos. Herbert Barker, M.D., F.R.S. Ed.-London, 1863. pp. 251.

9. Clinical Medicine: Observations recorded at the Bedside, with Commentaries. By W. T. GAIRDNER.-Edinburgh, 1862. pp. 741.

THE literature of fever has lately received accessions not unworthy the importance of the subject. Amongst the contributions of British observers, the work of Dr. Murchison and the Lectures of Dr. Tweedie occupy the most prominent position. The former comprises a most conscientious and painstaking inquiry into the identity or non-identity of the poisons producing the different forms of continued fever, an extended and laborious historical summary of the various epidemics which have been chronicled by successive generations of physicians, and an essay on etiology, geographical distribution, phenomena, diagnosis, prognosis, and treatment, which for scope, accuracy of observation, and research has seldom been surpassed. The publication of such a book marks an era in pyretology. Dr. Tweedie's lectures, also, the fruit of a long professional life devoted to the study and observation of fever, are in a practical point of view of high merit. To these we have added, at the head of this article, a list of works and pam- 
phlets, all of which, in differing degrees of excellence, are evidence of the attention which the subject is at present attracting, whilst several amongst them, as the Lectures of Dr. Anderson, the experimental essay of Dr. Barker, the Observations of Dr. Kennedy, and Mr. Hanbury's account of typhoïd fever in India, are valuable contributions to the scientific capital of medicine. The section of Dr. Gairdner's work on fever as seen in Edinburgh has already occupied our attention. But we shall have again occasion to examine its conclusions in the light thrown on them by facts obtained in other and more extended fields of observation.

Typhus, typhoïd or enteric, relapsing, and simple fever are the four forms almost universally allowed and recognised in England. Typical cases of typhus differ as clearly from typical cases of enteric fever as do cases of measles and scarlatina. Thus far there are few dissentients. But the closeness of relation existing between these forms, whether they be mere varieties or true species, whether their origin depend on one and the same cause, or whether the poisons producing them be entirely different, whether there be not a large class of indeterminate cases which it is impossible to refer with certainty to either form, these are subjects on which various shades and differences of opinion are still held by highly competent observers.

In discussing these and similar questions, the origin and affinities of simple fever need not be included. It is universally allowed that a non-specific febrile attack may result from exposure to the sun, fatigue, and excesses; that such a fever is non-contagious, and neither occurs as an endemic or epidemic. Limiting ourselves, therefore, to the consideration of typhus, enteric, and relapsing fevers, we may first inquire the grounds on which those who still assert the essential identity of these diseases base their arguments. It is clear that unless we are prepared to admit that not only the continued fevers, but small-pox, scarlatina, measles, plague, and the intermittent and remittent fevers, all have origin in one and the same cause, no argument can be founded on the broad resemblance of the phenomena of the febrile condition. In all we have the same elevated temperature, the same increased tissue-metamorphosis, the same affection of the nervous system, and in all we may have the same symptoms of uræmic poisoning (typhoïd symptoms) from the retention of the product of tissue-metamorphosis in the blood. It will also be at once admitted that some striking phenomena presented by two or each of the three diseases under consideration fail for the same reason to support the doctrine of identity of cause. Each of the group is contagious, although in different degrees, but so are plague and the true exanthemata. 'The activity of the contagious property in typhus and relapsing fever is far greater than that of enteric, but the tendency to spread by contagion in the two former is less than that observed in small-pox and scarlatina. Again, as in the exanthemata, one attack of typhus or of enteric fever confers an immunity from subsequent attacks, although there is now abundant evidence that typhus does not protect from enteric, nor enteric from typhus, any more than measles gives immunity from small-pox. To have suffered from relapsing fever does not shield the 
individual from subsequent attacks, nor from attacks of typhus, although it may be noticed that there are very few observed cases in which a person who has gone through an attack of typhus has contracted relapsing fever at a time when both diseases have prevailed. Wardell has recorded an instance in which relapsing fever occurred a fortnight after an attack of genuine typhus. Dr. Murchison observes that it is probable in some of the supposed instances of the occurrence of relapsing fever after typhus, the former disease was in reality enteric fever; but nevertheless, on the whole evidence, it seems clear that typhus does not afford the same degree of immunity from relapsing fever that it does from a second attack of typhus. Like also the true exanthemata, two members of the group, typhus and enteric fever, present distinctive cutaneous eruptions, which in well-marked cases are entirely different in characters, time of appearance, and course. Thus far, then, we have only evidence which in no way proves a closer relation between these fevers than may be safely asserted to exist between the exanthematous fevers, whilst the same resemblances might be urged to support an equally near affinity with the latter group.

The question then recurs, on what ascertainet facts do the impugners of the doctrine of non-identity of cause reason? One of the chief supporters of non-identity is Dr. Kennedy, of Dublin. This gentleman, whose large experience entitles everything he advances on the subject of fever to be received with attention, has, in his recent paper published in the last volume of the 'Dublin Quarterly Journal,' based an argument on the circumstance that cases which it is difficult or impossible to refer to either the typhus or enteric species are to be constantly met with. He impugns the value of Dr. Jenner's conclusions on the ground that they were based on 64 cases only, and that as these were all fatal, his conclusions were founded on a minority of instances, inasmuch as the majority of fever cases recover. He appeals to the evidence of Huss, whose observations were made on 3000 cases, and spread over twenty years, and who asserts the frequent occurrence of intermediate forms of fever exhibiting the symptoms of both petechial and abdominal (typhus and enteric), and the non-discovery of affection of the intestinal glands in cases marked by enteric symptoms; whilst, on the contrary, the specific lesions of typhoild were found by him in certain instances in which the symptoms exhibited the petechial character. Dr. Kennedy quotes the account given by Huss of an epidemic in which fever "broke out amongst 250 soldiers, all between twenty and forty years of age, and placed under exactly the like hygienic conditions, and yet the disease assumed the distinct form of typhus in one part of the cases, of typhoïd in another, and a third took an intermediate form"64 cases occurred. Huss also has recorded an instance in which, "in one house, 17 cases occurred within a fortnight, of which 10 were typhus and 7 typhoïd."

Another of Dr. Kennedy's arguments is based on his own experience as well as on that of Huss. It is that during the same epidemic the type of fever will undergo a change. At the commencement of the epidemics described by Huss, typhus was the prevailing form, whilst later enteric cases were more common. This fact is supposed to be 
more consistent with the hypothesis of one poison than of two. The occasional occurrence of ulceration of the ileum in cases of scarlatina and small-pox, as noted by Flint, Huss, and Anderson, is advanced to prove that there is nothing specific in the peculiar lesions of enteric fever. In fact, Dr. Kennedy goes so far as to hint that the ulcers of the ileum in enteric fever may, like the ulcerations of the intestinal glands in phthisis, be referable to the strumous constitution. He also urges, that certain symptoms which have been supposed by some writers to be characteristic of enteric fever, have been observed in typhus, and those of typhus in enteric. $\mathrm{He}$ instances the experience of Professor Flint, of Buffalo, who found that diarrhœa was present in one-half of the cases of typhoïd observed by him, and in one-third of the cases of typhus - a prominent symptom in the former cases, but mild in the latter; and who speaks of active persistent delirium as being characteristic of typhoïd. Dr. Kennedy refers to another symptom, intestinal hæmorrhage-supposed by Dr. Jenner to be characteristic of enteric fever-as having been observed by himself in 30 cases of well-marked typhus. In those of his cases, however, which were fatal, no ulceration was found after death. Epistaxis again, which has been far more frequently observed in enteric fever, is, according to Dr. Kennedy, equally common to both types. In his paper, Dr. Kennedy gives a short account of 40 cases of serious fever which came under his notice during two years commencing June, 1860. Amongst them he relates several cases that occurred in the first half of 1862 , in which, with a skin densely spotted, there existed diarrhœa and tympany. In the only one of these which proved fatal the ileum was not ulcerated, although it was very red in distinct patches, and the more so nearer the cæcum. The cæcum was ulcerated in patches, one of which was as large as a shilling, and there were small but distinct ulcers in the ascending colon. The glands were unaffected. This case proved fatal on the twenty-fifth day of the fever. The following is the summary which Dr. Kennedy gives of the two years' experience-

"With two points of exception they (the 40 cases noted) may, I believe, be taken as a fair sketch of the types of fever prevailing in Dublin within the last two, and some former years. These types were the typhus, typhoïd, and gastric. Leaving out the latter for the present, the reader will have observed the striking contrasts which these cases present: we find cases of typhus in both young and old;- of typhus without spots;-of typhoïd with none, with one or two, or with an extensive crop of them;- of typhus with the brain wonderfully free; - cases of typhoild, but more numerous, the same;of both typhus and typhoild, in which the state of the tongue and parts about were identical from sordes;-many cases of either type with the chest not engaged at all, or so slightly as not to call for treatment;-instances of both types with and without tympany; - cases of either kind entirely free from hæmorrhage, a freedom remarkable when compared with former years; - and lastly, the modified types of fever which the present year (1862) has disclosed." (pp. 20, 21.)

Another argument advanced by Dr. Kennedy against what he terms "these refinements in diagnosis," is the protean character of 
enteric fever. He appeals to the authority of Louis and Dr. Gairdner, now of Glasgow, both strenuous advocates of the doctrine of essential difference, in support of the difficulty of diagnosing typhoïd.

"Sometimes," says Louis, "the diarrhœa and meteorism were the most prominent; at times the depression of strength, delirium, spasmodic motions of all kinds; and according as one or the other was most prominent, the disease had the appearance of putrid or ataxic fever; sometimes, likewise, that of inflammatory fever; in some individuals there was no delirinm, or it was very slight, and, notwithstanding the most grave lesions, the calmuess continued until death. Notwithstanding these different aspects, the affection was constantly the same; the principal disorder did not change."

In a lecture, first published in the 'Lancet' of July 21st, 1860, Dr. Gairdner writes :

"Nothing then can be more variable or less characteristic than the general symptoms of the [typhoild] fever. I have seen it resolve itself in ten days with the symptoms of febricula, or of a mild remittent fever; I have seen it, on the other hand, last nearly as many weeks, and pass imperceptibly into organic disease. It mimics, in turn, not only all other fevers, but many other general or local diseases; phthisis, pneumonia, meningitis, perhaps more frequently than most others."

Before ending his chain of reasoning, Dr. Kennedy refers to the structural pathological differences which are supposed to mark the distinction between the two fevers. He argues that the case in which he observed ulceration of the cæcum and colon may fairly be referred to the enteric type, although the glands of the ileum had undergone no change ; first, because in a third of Louis' cases the colon and cæcum were affected, and, secondly, because it is generally admitted that " the affection of Peyer's glands does not necessarily bear a relative proportion to the fever." He also asserts, on the authority of Dr. Gordon, that cases occurred in the spring of 1862, in which ulceration of Peyer's glands was accompanied by the symptoms of typhus, "including a crop of genuine petechiæ." Dr. Kennedy winds up his argument by expressing his belief "that the two fevers known as typhus and typhoïd are the result of a single poison, and that no other hypothesis can explain so well all the difficulties of the case."

We have elsewhere observed that we are glad that this question has been thus reopened in this country, for assuredly there are few which have a more important bearing on hygienic and preventive medicine. We would allow to Dr. Kennedy's arguments their full power, but that they are strong enough to support the conclusion he draws is a position which a careful review of the whole evidence does not lead us to assume.

If we now turn to the writings of the supporters of the non-identity theory, we shall find that many of Dr. Kennedy's arguments have been anticipated, that others admit of answer, and that a different explanation may be given to his facts. It is true that cases do occur which it is difficult to diagnose, but, as long ago urged by Louis, the difficulty is not greater than is occasionally encountered in other diseases about which ordinarily there is none. Cases of scarlatina, and even of small-. pox, are now and then met with which are only recognised by external 
circumstances, and not by the intrinsic characteristics of the disease. The most characteristic symptom of typhoïd, the eruption of lenticular rose spots appearing in successive crops, may doubtless be absent, or so insignificantly developed as to be excluded in estimating the case. But so, in like manner, scarlatina fancium may exist without any efflorescence on the skin, and the nature of the affection might be entirely overlooked unless it were clearly traced to contagion, or happened to spread and give rise to the perfectly developed form of the disease in others. So with the mulberry rash of typhus, it also may be absent, but the disease in this form is capable of communicating the characteristic spotted fever to persons brought within its influence. As in the exanthemata, so both in typhus and typhoid, the eruption is the most diagnostic symptom, and when wanting in the case of enteric fever the difficulty of diagnosis may be insurmountable. In what proportion of cases this difficulty is likely to be met with in this country is shown by Dr. Murchison, who has examined the records of the London Fever Hospital, extending over a period of ten years. With regard to the eruption of enteric fever, Dr. Murchison
writes :

"The eruption is not invariably present, but is perhaps more common than is generally believed. Of 1820 cases admitted into the London Fever Hospital during ten years, it was noted in all except 224 , or $12 \cdot 3$ per cent.; and in many of the 224 cases, the fact of the spots not being observed was probably due to their not having been looked for with sufficient care. . . . They are more frequently absent in patients over thirty and under ten years of age, than in patients between ten and thirty. Of 1413 cases admitted into the Fever Hospital, between the ages of ten and thirty, the eruption was observed in all except 142, or 10 per cent.; of 252 patients over thirty, it was not observed in 40 , or in nearly 16 per cent.; and of 107 cases under ten, it was not noted in 37 , or $34 \frac{1}{2}$ per cent." (pp. 470,471 .)

In the case of typhus-

"Of 3506 cases, the eruption was noted in 3103 , and was not observed in 403 cases, or in 11.5 per cent. It was as often absent in males as in females; thus of 1737 males, it was absent in $193(11 \cdot 11$ per cent), and of 1769 females
in 210 (11.87). In children it was in $210(11 \cdot 87)$. In children it was oftener absent than in adults. Thus, the mean age of the patients in whom the eruption was present was 29.74 , and of those in whom it was absent only $26 \cdot 28$. Again, of 398 cases, where there 3058 cases with the eruption, only 444, were below 15 years of age, while of 3058 cases with the eruption, only 444 , or 14 per cent., were below 15 years.
In other words, of 563 cases below 15 years, the eruption was absent in 119 ,
or in 21 per cent., whereas of 2943 cases abous or in 21 per cent., whereas of 2943 cases above 15 , it was observed in all but 279 cases, or 9 per cent.; and of 17 cases below 5 years, it was absent in 7. These figures exaggerate the proportion of cases with no eruption, for in some it had no doubt disappeared before the patient's admission, and in others, where there was only slight mottling, it had probably escaped observation. Of 90 cases noted by myself in 1856 , the eruption was present in a!l but 6 patients, 3 of whom did not come under observation until a late period of the disease; and of 1107 cases admitted into the Fever Hospital during the first six months of 1862, the eruption was noted in all but 5]." (p. 130.)

The above extracts prove that there is always a certain proportion of cases in which the sign which furnishes beyond doubt the most 
certain criterion is absent; but whilst the same may be affirmed of a large number of other diseases, subordinate points of resemblance cannot prove identity of cause as long as a majority of typical cases of both fevers occur which are as clearly and specifically different as any generically allied nosological species. The confusion depends on the imperfections of our powers of diagnosis; it is not chargeable on the order of Nature.

We should pass over Dr. Kennedy's comparison of the extent of Jenner's observations with those of Huss, merely remarking that Jenner's cases, although few in number, were most accurately observed and described, whilst, as is pointed out by Dr. Murchison, Huss includes all the spots met with in fever, which are neither petechiæ nor sudamina, under the term taches lenticulaires (synonymous with his eruption typhoïde), confounding therefore the florid spots which in typhus precede, and are converted into petechiæ, with the lenticular rose-spots of enteric fever-a fact that entirely explains his assertion of the frequent co-existence of taches rosées lenticulaires with the petechiæ of typhus. But it is to be remembered that ever since the publication of Dr. Jenner's memoir, which first brought conviction to the minds of English physicians of the essential difference of the two forms of fever, testimony on the point has been steadily accumulating.

In the first place, there is the mass of evidence accumulated at the London Fever Hospital. From the register and case-books of that hospital, Dr. Murchison has ascertained that 5326 patients suffering from the two forms of fever were admitted during ten years. Of these, 3506 cases were diagnosed as typhus, and 1820 cases as enteric fever. It frequently happened that several members of one family or residents in one house were admitted at one time, or followed each other in quick succession. But with two exceptions, cases of typhus and enteric were never brought from the same house, except after the intervention of months or even years. One of the two exceptions is well known, it having been investigated by Dr. Jenner. "A boy, aged sixteen, was admitted on September 19th, 1848, with enteric fever, and on October 10th his father was admitted with typhus. But the mother of the boy had visited him in the Fever Hospital, whence she might have catried the poison of typhus to her husband. The father, moreover, had been little exposed to the contagion emanating from the son, who, being a vagabond at variance with his father, was from home when he was taken sick." The other exception admits of ready explanation. In November and December, 1851, four servants suffering from enteric fever were admitted from a hotel in the Haymarket. In the following January a servant was admitted with typhus from the same house. But the typhus patient was one of the four who had previously had enteric fever. She had only left the Fever Hospital about ten days when she was re-admitted, and the typhus by which she was attacked had doubtless been contracted during convalescence in the hospital. These observations have been verified at other of the London hospitals. Dr. Murchison quotes the experience of Dr. A. P. Stewart at the Middlesex Hospital, of Drs. Peacock and Wilks at the Royal 
Free, St. Thomas's, and Guy's Hospitals, each of whom has invariably found the same distinction of origin. In Edinburgh valuable and, from the limit of the area of observation, even more crucial evidence has been given by Reid, Goodsir, Waters, Robertson, and Gairdner. The following extract is from Dr. Gairdner's work:-

"There is this advantage in a small field, that you can be much more sure of exhausting your facts. No one can pretend to have had access to all, or nearly all the fever cases of London, during however short a period. But in Edinburgh, Dr. Begbie and myself probably have seen, or have had the means of knowing about, very nearly all the fever cases; and therefore, when I declare to you that within my experience for ten years past, no instance has occurred of a decided origin of enteric fever in a group of typhus cases, or of typhus fever in a group of enteric cases, I am entitled to say that I have obtained very strong evidence in corroboration of the view that these two diseases are in reality different diseases, and not mere varieties of the same disease. Last summer I made a very careful survey of the whole fever-field of Edinburgh (if I may call it so) for several months together. It was not an epidemic season; but I gathered about thirty cases of typhus and twelve of enteric fever, and into the whole details of these I inquired with the greatest possible minuteness, visiting every one of the fever localities, except one or two in which I was quite sure that the cases were isolated. The result was that in no case could I light upon a suspicion that typhus had given rise to anything but typhus, or enteric fever to anything but enteric fever. The details of this inquiry were published in September, 1859." (pp. 119, 120.)

Since 1859, Dr. Gairdner has pursued the same line of investigation, and the results are in exact accordance with those to which he had been previously conducted. We might bring other testimony to bear out the same conclusion. Dr. Murchison quotes Dr. A. P. Stewart, to the effect that, during the years 1836-37-38, the latter saw upwards of 3000 cases of fever in Glasgow, but in no instance did he see typhus and enteric occurring together in the same family or house. It may, however, be argued, that one positive fact is worth a large number of negative ones, and that the little epidemic amongst the soldiers, and the cases of enteric and typhus observed by Huss in one house, cannot be easily set aside by any amount of non-occurrences. If we admit the accuracy of Huss's observations it by no means follows, however, that they warrant the conclusions which himself and Dr. Kennedy would draw from them. In the first place, if typhus and enteric fever arise from the same poison-if they are mere varieties of the same disease-instead of Huss's facts being derived from one small epidemic and one house, they ought to be furnished by every epidemic and in the majority of instances. The paucity and rarity of the facts is a powerful argument against the meaning which they are supposed to convey. 'They are perfectly explicable on the assumption of the occasional co-existence of two distinct poisons, but from their very fewness they are inexplicable on the assumption of the sole existence of one poison which is capable constantly of producing two diseases. No one contends that small-pox and scarlatina are the product of one morbid poison, because in a particular epidemic they are co-existent, or because, as in a case lately observed by ourselves, they have appeared in the same house within a few days of each 
other, and no such deduction can be safely drawn from the not infrequent prevalence of typhus and typhoïd fevers in one season, or the occasional, although very rare, appearance of the two diseases in the same house or family.

With regard to the occurrence of intermediate forms in the course of an epidemic season when both typhus and enteric feverare prevalent, we may safely refer the large majority of their examples to faulty diagnosis, dependent either on the absence of eruption or on an unusual development of the symptoms of uræmic poisoning (typhoïd symptoms) in enteric cases-by no means an unfrequent occurrence, and a probable explanation of the cases we have instanced in our review of Dr. Gairdner's work-or, as in the work of Huss, on the want of a just discrimination between the early stage of the rash of typhus and the eruption of typhoïd. But it by no means militates against the specific difference of the two poisons to admit that a person may at one and the same time be under the influence of both, and may thus exhibit signs and symptoms of a mixed character. This is no more than has been observed in the case of other diseases, such as variola and scarlatina, and variola and measles. In vol. xxx. of the "Medico-Chirurgical Transactions' is a paper by Mr. J. F. Marson, referred to by Dr. Murchison, in which the writer states that he had seen in the Smallpox and Vaccination Hospital, in the course of eleven years, seven persons who had small-pox and scarlatina simultaneously; whilst he adduces a number of authorities who have noticed the co-existence not only of small-pox and scarlatina, but of small-pox and measles, small-pox and hooping-cough, and hooping-cough and measles. The old Hunterian doctrine, "that no two different fevers can exist in the same constitution, nor two local diseases in the same part, at the same time," has been long exploded, together with many other theories which the authority of Hunter invested with the dignity of doctrines. Dr. Murchison has demonstrated in his work, that scarlatina may be found occurring with enteric fever, and typhus may be engrafted on small-pox. Of the former, he has noticed 8 cases; of the latter, 1 case occurred at the Fever Hospital, under the care of Dr. Buchanan. Unless, therefore, these diseases have a common origin, the co-existence of typhus and enteric fever in certain rare cases caunot be urged in proof of their identity. Three instances of such co-existence have been noticed by Dr. Murchison at the London Fever Hospital. In two of these the patients were admitted with enteric fever, were exposed to the contagion of typhus in the wards, and contracted the latter disease. The third was originally a case of typhus. The earlier symptoms of the third case were a well-marked typhus eruption, composed of spots and mottling; a dry, brown tongue; confined bowels; heavy, confused expression; small pupils; and low, wandering delirium. The typhus eruption faded on the eleventh day, "and was succeeded by lenticular rose-spots, which came out in successive crops for more than a week, and were accompanied by diarrhœa, abdominal tenderness, red tongue, and dilated pupils." The patient had been subjected to the contagion of typhus, but had also been brought from an ill-drained and very offensive house. In the first case 
mentioned by Dr. Murchison, it was not until the boy had been exposed in the ward from June 3rd to June 17th, and on the twentysecond day of his illness, that the typhus eruption was superadded to the already existing rose-coloured spots of his original disease ; the two were co-existent from June 17 th to June 21 st ; the typhus " mottling" continued until June 26th. Such cases, and the frequent contraction of typhus by patients convalescent from enteric fever, who have been exposed in hospitals to the contagion of the former, is a powerful argument for the adoption of separate wards for each form of disease. It is manifest that the change of type observed by Huss and Kennedy in the same epidemic period is as explicable on the supposition of two poisons, the one exerting the greater influence during one portion of the period, the other at another, as of one poison modified and altered by some unknown cause. In the face of the vast mass of evidence accumulated in support of the essential difference of the two fevers, we think we are bound to adopt the former theory until there be distinct proof that the contagion of typhus can produce enteric fever, and that of enteric can give rise to typhus.

That there is nothing specific in the intestinal lesions of enteric fever, and that this is proved by rare and exceptional cases of ulceration of the ileum in scarlatina and small-pox, and by the occurrence of intestinal ulcers in phthisis, bearing some resemblance to the ulcers of typhoïd, is an argument which we believe will not stand investigation. Flint, Huss, and Dr. Anderson of Glasgow, have recorded four cases in which ulcers of the ileum occurred in scarlatina. Dr. Anderson has also related an instance of confluent small-pox in which there was the same lesion. As his cases, and the context in which they are mentioned, have a most important bearing on the subject under consideration, we shall here quote them in full :

"We now come to inquire what relations, if any, exist between typhus and the enteric fever. 'Glaring instances' of the diseases, as we have seen, are sufficiently distinct; their symptoms, course, and morbid anatomy being utterly diverse, except in so far as any two fevers may assume types and phases which bring them, therapeutically considered, into alliance. But what are we to make of cases like that which I shall now read to you from my note-book?

"J. F - , aged twenty-seven, a domestic servant, died on the eighteenth day of a fever characterized by the presence of a very copious and livid typhous eruption over the body and extremities. On inspection of the body we found the mucous membrane of the duodenum covered with enlarged solitary glands,
softened and ulcerated, so that in some places the peritoneum alone remained of the coats of the bowels. Peyer's glands were enlarged throughout the greater pait of the jejunum and ileum, a patch in the lower part of the latter being about five inches long. and an excavated ulcer existed in its vicinity. The small and large intestines were besprinkled with numerous enlarged soli-
tary follicles.

"The generalizing faculty would readily conclude from this case that typhus and enteric fever are identical; but listen to two more:

"Jane S - died of æsthenic confluent small-pox, at the period of maturation. On opening the body we found on the mucous surface of the ileum a number of enlarged Peyer's glands, two of which were ulcerated.

"Mary S—, aged sixteen, was adnitted on the fourth day of fever. There 
was copious scarlatinous efflorescence; she had sore throat, and a tongue white and florid at the tip and edges. 'Two days after, she died, having passed a large quantity of blood by stool. On inspection we found the whole of the ileum of a deep red on its mucous surface, and thickly besprinkled with enlarged solitary follicles. Peyer's glands were also much enlarged and ulcerated, and many swollen follicles were scattered over the colon.

"Now can we suppose it possible that small-pox, scarlatina, and typhus are all identical with enteric fever, because these cases prove that the special lesions of that disease may coexist with each of them?-Thus, by a reductio ad absurdum, the position falls." (pp. 114, 115.)

Dr. Anderson then relates a case of typhus occurring during convalesoence from enteric fever in proof of their non-identity, and proceeds to explain the cases we have quoted on the supposition that the lesions were the result of enteric fever "mixed up" with typhus, variola, and scarlatina. The coexistence of the latter group with intestinal lesion, he remarks, "is no greater proof of their identity than a man's having the misfortune to break both his arm and his leg by a fall would be a proof that these injuries were, in fact, the same." It will be observed, however, in reading these cases, that no mention is made of any enlargement of the mesenteric glands, a constant concomitant of the intestinal lesions of enteric fever. It may also be doubted whether the ulceration which was found were the real typhoild lesion. In the case of fever the duodenum was extensively diseased, its solitary glands enlarged, softened, and ulcerated-a comparatively rare occurrence in enteric fever. In 15 cases examined by Jenner, and in 20 dissected by Murchison, there was no ulceration in this portion of the intestine. With regard to the cases of scarlatina and variola, it may be observed that not only in these diseases, but in cholera, erysipelas, and pyæmia the solitary and agminate glands of the ileum are occasionally enlarged, and may in solitary instances be found ulcerated, although the small, shallow ulcers then occurring are very different from the ulcers of enteric fever. It will also be observed that Dr. Anderson does not describe the characters of the ulcers he found. It is quite possible, however, that his own explanation is the correct one, and that in these instances two different diseases were simultaneously producing their effects. But when we turn to the positive evidence of the occurrence of intestinal lesion in enteric fever, and of its absence in typhus, the weight of proof, we think, becomes conclusive. During the past fourteen years many hundreds of bodies have been dissected at the London Fever Hospital, and in every case in which during the course of the fever successive crops of lenticular rose spots had been observed, the abdominal lesions of enteric fever were invariably present, whilst in every case marked by the characteristic rash of typhus the abdominal lesions of enteric fever were as invariably absent. Dr. Murchison asserts expressly that there have occurred no exceptions to these broad facts. It is true that in typhus the intestines are not always healthy, but what are the characters of the lesions they present? In 15 of 75 cases observed by Jenner and Jacquot, the duodenum presented various degrees of softening and injection. Softening and injection of the mucous membrane of the jejunum and ileum have also been observed in a small propor- 
tion of cases by the same investigators and by Reid. In 50 cases of typhus examined by Gerhard and Pennock, of Philadelphia, in 1836, Peyer's glands were entirely unaffected in every instance save one, and that a case of doubtful diagnosis. In this the agminated glands were reddened and a little thickened, but there was no ulceration or deposit in the submucous tissue. Of the cases examined by Dr. A. P. Stewart, at Glasgow, in 2 out of 21 the patches were slightly elevated; but he says expressly that the appearance was not that characterizing enteric fever. In Dr. Jenner's 43 cases, Peyer's patches were healthy in all save 3 ; in one there was tubercular ulceration, in a second there had been dysentery, and the inflammation extending high up the ileum had involved the mucous membrane covering the patches; in the third there was mere injection of one patch, but no ulceration. Similar evidence has been given by Drs. Peacock and Wilks, by Jacquot in his work on the typhus of the Crimean campaigns, by Barrallier in his history of typhus as it occurred at the hulks of Toulon. Barrallier observes: "Je ne jamais observé sur les 166 sujets nécropsiés pendant les deux épidémies du bagne, aucune des altérations des plaques de Peyer et des follicules de Brunner, que l'on rencontre dans la fièvre typhoïde." Godelier bears the same testimony with regard to 8 fatal cases of typhus examined by him in the hospital of Val de Grace ; and lastly, Dr. Murchison, who has dissected 54 cases, asserts :

"In not one was there any deposit in or ulceration of Peyer's patches, at all resembling the appearances found after death from 'typhoïd fever.' In six only of the cases the glands were slightly more prominent than usual, but not more so than is seen after death from many diseases. In three of the six cases, the glands presented the appearance compared by French pathologists to a newly-shaven beard.” (p. 233.)

With regard to Dr. Kennedy's case, in which the cæcum and ascending colon were the seat of ulceration, it may be observed that injection, inflammation, the effusion of lymph in patches, and ulceration of the large bowel, have all been observed in typhus. Dysentery is, in fact, a not unfrequent concomitant of the fever, and in the absence of the characteristic affection of the glands of the ileum, ulceration of the great intestine is no proof of close relationship between the typhus
and enteric species.

Again, all observers who have had considerable opportunities of observing the peculiar alterations produced in the agminate and solitary glands in enteric fever, are agreed that they present essential differences from the tuberculous ulcers met with in phthisis. The first
stage of the typhoïd lesion consists in the deposition of morbid material. This has been found as early as the end of the first day of the disease, although Trousseau's observations led him to conclude that it did not occur before the fourth or fifth day. The two varieties of the diseased fever-the plaques dures found about the eighth or tenth day of the are believed by Dr. Murchi plaques molles of French pathologistswhich, with Goodsir, he asserts is obend on the amount of the deposit terior of the glandulæ. In the observed in the first place in the in- 
quantity, and is retained in the glandules which give the rugose character to the patch peculiar to this form of affection; in the plaques dures the glandules burst and discharge their contents into the submucous tissue, and hence the patch presents a smoother surface. In the second stage ulceration commences. In the case of the plaques molles, the mucous membrane softens and becomes abraded in one or more places, which unite and extend into one large ulcer, which may extend to various depths through the subjacent tissue. In the plaques clures the whole of the diseased patch, with the superimposed mucous membrane, becomes detached either in one or more sloughs, leaving behind an ulcerated surface. Between the twelfth and twenty-first days these sloughs will frequently be found loosely attached to the ulcers, coloured yellowish-brown from the imbibition of bile, or having a dark spongy aspect from infiltrated blood. The third stage is the period between the separation of the morbid deposit or of the sloughs and the commencement of cicatrization. It is then that the typhoïd ulcer presents its characteristic appearance. Seated in the lower third of the small intestine, increasing in number as the ileo-cæcal valve is approached, they are of different sizes, from a line to an inch and a half in diameter, whilst in close proximity to the valve several ulcers may run together, producing an excavated surface of several inches in extent. If the ulcer correspond to an entire Peyer's patch, it is elliptical; if to a solitary gland, circular; or irregular in the case of the union of several ulcers or the destruction of only a portion of a patch. They are situated in the part of the intestine opposite the attachment of the mesentery, and their long diameter corresponds with the longitudinal axis of the gut. They do not form a zone encircling the intestine, as may sometimes be noticed in the case of tuberculous ulceration. Their margin is formed of a well-defined firinge of mucous membrane detached from the submucous tissue, which is well seeu on floating the intestine in water. There is no thickening or induration of the edge, or deposition at the base of the ulcer, though sometimes fragments of yellow sloughs may be found adhering in these situations. Such is the description given by Dr. Murchison of the special lesion of enteric fever. Dr. Tweedie's account closely corresponds with it, and both descriptions entirely agree with that of Rokitansky. We need not describe the fourth stage of the ulcer-that of cicatrization. We have dwelt thus long on the subject to enforce the differences between these lesions and those of phthisis. In the latter, if the ulcerations be large, they extend round the circumference of the intestine; their bases and edges are thickened and indurated with tubercle, which gives them a cup-shaped appearance, and although the agminated and solitary glands of the ileum are affected as in typhoïd fever, and hence the locale of the two species of lesion is the same, yet in phthisis ulceration extends beyond the glandular patches, frequently to a considerable extent, and we frequently find tubercular depositions, the hard semi-cartilaginous-like granulations of Louis, or tuberculous granulations in the process of softening in other parts of the intestine, sometimes over its entire tract. Lastly, the cicatrization 
of the ulcers of enteric fever does not cause any diminution of the calibre of the gut, whilst, according to Louis and Corbin, tuberculous ulcerations frequently entail contraction of the gut around them.

That the occurrence of diarrhœa, intestinal hæmorrhage, tympany, and epistaxis, in a minority of cases of typhus fever, and of "typhoïd," and head symptoms in those cases of enteric fever to which we have already referred, is no argument for their essential identity, scarcely requires demonstration. Cerebral and the so-called "typhoïd" symptoms are not peculiar to any of the idiopathic fevers. They are in all probability directly caused by the imperfect elimination of the products of increased tissue metamorphosis from the system, and if the occurrence of convulsions or stupor, of low muttering delirium and contracted pupil, of dry brown tongue and sordes in cases of enteric fever, prove it to have the same cause as typhus, they will equally prove that all cases of uræmic poisoning are produced by typhuspoison. The symptoms have doubtless a common cause, but that cause may be the concomitant of any idiopathic fever, as well as of many other affections. So also hæmorrhages from the mucous tractspetechiæ in the true sense of the term-diarrhoa, and tympany, are phenomena which are not in themselves specific. Petechiæ- the escape of dissolved hæmatine into the cutis-take the place of the true eruption of typhus in most cases of that fever, but they are neither essential to nor diagnostic of the disease; they occur in other fevers, often in relapsing, more rarely in enteric, and they are seen in the latter stages of various non-febrile maladies. It is true that the diarrhœa of enteric fever is peculiar in character, and occurs in a large proportion of cases. The yellow-ochrey appearance, offensive ammoniacal odour, and alkaline reaction of the stools, due, according to Dr. Parkes, to carbonate of ammonia, are characteristic. But diarrhœa is not constant. It was absent in 7 of 100 cases noted by Murchison, and in 4 there was absolute constipation. Similar observations have been made by every observer, and the same is true of hæmorrhage from the bowels, epistaxis, dilatation of the pupil, abdominal pain and tenderness, meteorism and gurgling. They are all commonly met with in typhoid fever, but they are neither peculiar to it nor necessary to its existence. On the other hand, whilst constipation is the rule, it is no new observation that diarrhœa occasionally complicates typhus. Dysentery, as we have already noticed, may be its concomitant; although they are not frequently seen together in the epidemics of England, their coincidence has been observed in some epidemics in Ireland, and was common in the French army in the Crimea. When diarrhœa or dysentery occur in typhus, they may be attended with abdominal pain and meteorism; and especially if the disease be complicated with scurvy, but even withont such complication, hæmorrhage from the bowels or epistaxis may also possibly be encountered. With regard to intestinal hæmorrhage, Dr. Tweedie's experience furnishes a well-marked case of typhus in which it proved fatal. He observes:

"Intestinal hæmorrhage is peculiar, or nearly so, to enteric fever, for although it may occur in ordinary typhus, it is very rare. I had a case of typhus in the 
hospital some time ago, in which this appeared to be the destroying cause; and on opening the body, Peyer's patches were found to be sound, but the mucous membrane of the lower portion of the ileum, cæcum, and commencement of the colon exhibited a red swollen appearance. In this patient there was the well-marked mulberry (typhus) eruption to assist the diagnosis. (p. 72.)

The intestinal hæmorrhage of enteric fever is only peculiar as an accident dependent on the specific lesions of that disease. When, as in Dr. Kennedy's thirty cases before referred to, it arises independently of any specific ulceration, it proves no closer connexion with enteric fever than it does with purpura hæmorrhagica, or malignant smallpox.

Neither does the protean character of enteric fever sustain in any degree Dr. Kenuedy's argument. Typhoïd fever is, in the vast majority of cases, far more easy to discriminate than acute phthisis, and we may state on the authority of Dr. Walshe, that the diagnosis between acute phthisis and enteric fever is sometimes a matter of the greatest difficulty. But no one on that ground would argue that the two diseases had one and the same cause.

Dr. Kennedy, following Huss, founds an argument on the analogy of scarlatina, which, he asserts, presents just as striking differences in itself as do the typhus and enteric fevers. Without staying to inquire whether the differences in scarlatina are not differences in degree rather than in kind, there is one fact which affords a complete answer to this reasoning. The mildest case of scarlatina may give rise by contagion to the most malignant. The contagion of typhus has never been proved to give rise to typhoïd in persons exposed to it, nor that of typhoïd to typhus.

We have thus far confined ourselves to the special consideration of Dr. Kennedy's arguments. But there are differences between the two species of fevers which his reasoning leaves entirely untouched. In the first place, the history of typhus is a history of great epidemics. This is written on every page of the epidemiology of Europe from the times of Fracastorius of Verona and Cardanus of Pavia to our own. On the other hand, enteric fever, wherever it has been distinguished, has been found to prevail endemically over smaller areas. Our limits do not permit us to illustrate this point; we can only refer our readers to the admirable history of the two diseases compiled by Dr. Murchison. The geographical distribution of the two fevers, as far as it has been ascertained, is not the same. The great habitat of typhus has hitherto been the temperate latitudes of Europe and North America. It has prevailed in every country of Europe from the Crimea to Sweden, and although it has not been recorded as occurring amongst the Laplander 3 and Esquimaux, the writings of Schleisner appear to prove that it has often swept over Iceland. In Britain and in Ireland, it has ever been peculiarly rife, and it has also spread amongst the populations of Canada and the American States. It has not hitherto been observed in Australia or New Zealand, and there is no satisfactory evidence of its occurrence in Africa, Asia, or the tropical parts of America. It is true that cases of so-called typhus have been reported in India, Brazil, 
Mexico, and other parts of South America, but the descriptions given of the disease when critically examined do not answer to the well-known European typhus. We must allow that this argument will be weakened, if Dr. Murchison's opinion of the close analogy, if not identity, between typhus and bubonic plague be hereafter found to be correct. Unlike typhus, however, enteric fever appears to be a denizen of all countries and all latitudes. Not only in nearly every country of Europe is it endemic, but its existence in India is now established by numerous observers. Mr. Hanbury's account of the occurrence of enteric fever at Deesa is additional evidence on this point. It is true that in his cases the rose-coloured eruption was not observed; this he attributes to the fact that the patients were covered with prickly heat -lichen tropicus-but ulceration of the agminate glands was found in every autopsy, and the cause of the fever was clearly traced to open cesspools and sewers. Typhoild fever has been seen by the French in Algeria, and has been noted by Griesinger in Egypt, by Oelsner in the Isle of Bourbon. The late Dr. McWilliam encountered it in the illfated Niger expedition, and there is also other evidence that it is one of the fevers of Sierra Leone. Enteric fever is endemic in North America, from Greenland to the Gaif of Mexico. It occurs in Central A merica and California, and is reported as extremely common in Brazil and Peru. The same fever has been also found in New Zealand and Van Dieman's Land. Again, typhus may occur at any age, but is essentially a disease of adult life; enteric fever, on the contrary, although not confined to, is most common during the periods of youth and adolescence. The contrast between the two fevers in this respect is amply shown by the records of the London Fever Hospital. The following table, constructed by Dr. Murchison from the register of 3456 cases of typhus and 1772 cases of enteric fever admitted during ten years well illustrates this point of difference.

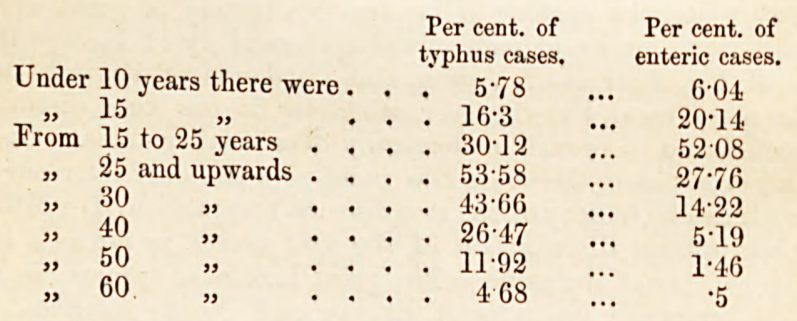

Dr. Murchison argues justly that the real comparative liability to typhus at ages above thirty is much greater than these numbers at first sight show, because the total population above that age is scarcely more than one-third of that below, and in a certain proportion of individuals, the liability to take the fever will have been removed by their already having passed through it. In the case of enteric fever, on the other hand, it follows, from the smaller relative number of the population above thirty, that persons under that age are twice as liable to this form of fever as persons over thirty. Another point of diffe- 
rence is the duration of the two diseases. The mean duration of 53 uncomplicated cases of typhus in which recovery took place, observed by Dr. Murchison, was $14 \cdot 13$ days; that of 10 uncomplicated fatal cases was 15 days; but the mean duration of 75 cases of enteric fever which recovered was $24 \cdot 6$ days; and that of 12 fatal cases of the same fever was 22.08 days.

There is another most essential point of distinction between the two fevers, with which is bound up much of the practical importance of the whole question of their community or diversity of origin. We mean the difference in the activity of their contagious properties. The belief that typhus is contagious has now received such abundant support from such various sources that we shall make no extracts from the numerous facts which Dr. Murchison has collected in its support. The contagious properties of enteric fever, on the other hand, are so feeble in their development that they are denied in toto by many most competent observers, as Andral, Chomel, and others. Nevertheless, the cases collected by Dr. Murchison, although few in number, leave little doubt of the possibility of its being communicated by the sick. From them we extract the following:-

"In the year 1858, one of the nurses at the King's College Hospital, between twenty-five and thirty years of age, contracted well-marked pythogenic fever, and died. Immediately before her seizure, she had been engaged in nursing a patient ill of the disease. None of the other nurses or patients in the hospital caught the fever, which could not therefore be supposed to have a local origin."

"Some years ago two young men met in London: A. came from the Isle of Wight, where there was no fever; B. came from a village in Cambridge, where pythogenic fever was prevalent. B. was ill at the time of meeting. Both proceeded to Edinburgh, where B. had a well-marked attack of pythogenic fever. A. lived in the same house, and nursed B., and he also took the fever, although all the other residents in the house escaped." (p. 431.)

Another case, of even a still more convincing character, is quoted from Dr. W. Budd-

"On the 16th of December, 1858, a lad about twelve years old was brought from a boarding-school, at Cardiff, in the first stage of pythogenic fever, to his father's home, which was a farmhouse, situated on the crest of a hill, five miles to the west of Cardiff. Fever had not occurred at this farm within the memory of man. Before the arrival of the infected lad the family were in the enjoyment of good health, and the neighbouring village and farms were entirely free from fever; yet shortly after his arrival, three sisters, two brothers, two servants, and a hired nurse all contracted the fever." (p. 433.)

Yet the contrast in the activity of contagious property is well shown by the broad fact, that during Dr. Murchison's connexion with the Fever Hospital, only 2 cases of enteric fever have appeared to originate there, although 1048 cases have been admitted; whilst in the same period, 36 of the patients and attendants have contracted typhus, the number of admissions of that disease having been 2581 .

Whatever the specific poisons of typhus and enteric fever may be, whether they originate de novo, or whether pre-existing germs are only called into activity under certain conditions, the conditions under 
which their genesis takes place or their activity is called into play, appear to be essentially different. For the origination or development of the typhus poison, the circumstances necessary are the over-crowding of squalid human beings with deficient ventilation, whilst among the most powerful predisposing causes are starvation and destitution. These facts are proved by the history of gaols, ships, workhouses in time of famine, beleaguered garrisons and armies. The circumstances giving rise to enteric fever, on the contrary, are neither overcrowding nor deficient ventilation, although the latter, by preventing the diffusion and dilution of the poison, may enhance its activity. The facts collected by Dr. Murchison go far to prove that enteric fever is contracted during exposure to emanations from sewage and putrefying fæcal or animal matter, or by such matters being conveyed into the system through the medium of drinking water. Whether, as Dr. Murchison believes, the poison of enteric fever is generated spontaneously by the fermentation of fæcal matter, or whether, as is maintained by Dr. W. Budd, the poison, although contained in the sewage, is always derived from the alvine evacuations of a person suffering from the disease, in which excreta the poison is concentrated, the drain or sewer becoming "a direct continuation" of the diseased intestive, is as yet an open question. Dr. Budd's view is certainly supported by the fact of the contagious properties of enteric fever, but it does not admit of proof, whilst we are utterly ignorant of the true nature of the poison. On the other hand, the arguments and facts adduced by Dr. Murchison against it are not readily answered. He instances several outbreaks in which it is most difficult to conceive that the poison could have been introduced into the drain, some cases in which the source of fever appeared to be the decomposition of sewage in drains which had been previously choked up and cut off from the general drainage, and others where enteric fever has arisen in isolated country houses and villages far away from any source whence it might have been imported. He argues, that enteric fever should more constantly spread in fever hospitals, where nurses and patients are constantly exposed to emanations from the night-stools, if the poison
passed in its full potency from the diseased intestines of the patients.
He states that he fed a pints He states that he fed a pig for six months on the stools of patients
suffering from enteric suffering from enteric fever; the animal got fat, and when it was killed its intestines were perfectly healthy. The condition of the stools in enteric fever he supposes to be inimical to the existence of an animal poison, analogous to that contained in the pus of small-pox. The stools are invariably alkaline, charged with the products of the niaco-magnesian phosphate and the form of ammonia and ammoniaco-magnesian phosphate, and they always exhibit the greatest tendency to decomposition or fermentation. The sloughs cast off from the ulcerated intestines are dead and putrid, and therefore, from the analogy of the poison of vaccinia and variola, should cease to exert any effect, even if we suppose the poison to reside in the morbid deposit. Lastly, he contends that the influence of temperature on the activity of the poison is more in unison with the supposition that it 
is the result of fermentation or decomposition, than with that of its existence as a specific poison derived from the sick.

These arguments are not conclusive; but they must be allowed to throw considerable doubt on the theory advanced by Dr. Budd and Professor von Gietl. On the other hand, there are sufficiently close points of analogy between all the exanthematous and continued fevers to suggest strongly the idea that their poisons, although specifically different, are generically allied. And whilst we have the best reason for believing that of small-pox to be organic matter, we shall not readily refer those of the other members of the group to the inorganic world. One thing is, we think, certain, that none of these subtle agents can have their origin apart from animal matter; they cannot be produced by vegetable decay, and it is yet to be proved that they can be imitated by the combinations of the laboratory. It is not sufficient to show that "patches of ulceration may be produced along the intestinal canal of a dog, by making it inhale sulphide of ammonium, as has been asserted by Dr. Richardson, although this is scarcely supported by Dr. Barker's experiments, who found that the intestinal mucous surface, under similar circumstances, was only "somewhat injected " or that diarrhœa and vomiting should be observed in animals made to breathe sulphuretted hydrogen or cesspool gases: we must have evidence that a fever with a definite eruption, a regular course, the power of propagation by contagion, and the occurrence of which shall protect from a second attack, can be so generated, before the requirements of the problem can be held to be worked out. We would here, however, guard against being misunderstood: we do not contend that the poisons are anything more than organic matter, analogous, it may be, to the poison of hydrophobia or syphilis; we do not assert that they exist as distinct organisms, and we are ready to admit that there is the highest probability that they may originate de novo. The latter admission, however, is not fatal to the supposition that they are propagated as organized germs, at least it cannot be held to be so until the vexed question of spontaneous generation is finally set at rest. Dr. Barker, whose experiments on the gaseous poisons are of the highest interest, insists strongly on the fact that inorganic poisons, although they may produce symptoms which shall imitate those of the continued and exanthematous fevers, do not give rise to the diseases themselves. We quote two paragraphs from his concluding summary-

"The fact of the organic nature of the poisons (producing typhus and typhoïd fevers, cholera, and the exanthemata) is proved by their power of reproduction, their communicability from person to person, their destruction at a temperature extremely high, and the suspension of their activity as poisons at a temperature extremely low." (pp. 223-4.)

"Inorganic poisons are not competent to the production of communicable disease, the symptoms they produce being confined to the body in which they (the symptoms) are demonstrated." (p. 226.)

In this review we have examined the arguments for the identity of the poisons producing typhus and enteric fever, impressed with the conviction that it is of the highest importance that their difference, if 
it exist, should be acknowledged in all measures taken for the prevention or arrest of these diseases. We believe that the balance of evidence is in favour of the opinion that these poisons are different species, as distinct as the species of undoubted and complex organisms. Whether such gradationary varieties may exist between them as are at all analogous to those which in the vegetable and animal world make the definition of the terms species and variety the naturalist's difficulty, is a question which can only be answered by accumulated observations. It cannot be held to be at present settled in the affirmative. Practically, we are forced to the conclusion that the different species of fever, and their producing poisons, form well-defined separate groups, which cannot be confounded without abrogating all nosological distinctions.

Finally, there is an argument derived from the treatment of these fevers which bears strongly upon the question of their identity. It is thus stated by Dr. Tweedie, the therapeutical portion of whose lectures we should gladly have analysed for our readers had space per-
mitted-

"The results of the treatment of the two forms should not be overlooked in discussing their identity. As a general rule, we find that remedies have a much more striking influence on the one than on the other. Stimulants are more early required, and to a much greater amount, in typhus; and if any local complication arise in enteric fever, depleting remedies are much better borne than in typhus. I remember Dr. Jenner remarking to me, as he investigated the records of the cases kept in the Fever Hospital, that when the leading characters of the two diseases had not been noted, or, at all events, so carefully as they have been within the last decennial period, he could, in the absence of the diagnostic symptoms, form a tolerably good idea of the type of the disease by the treatment that had been adopted; for while in the typhus cases considerable quantities of wine and brandy had been prescribed, in the enteric, stimulants had been either withheld or administered in sparing amount." (pp. 43-4.)

In this review it will be observed we have abstained from making use of the term "pythogenic," proposed by Dr. Murchison for enteric fever. Our reasons have been that the use of the word pledges to the reception of a theory which, however probable, cannot at present be held to be undoubtedly established, and we are adverse to the introduction of a new name in a nomenclature already redundant. The term "enteric," although in the first instance coined under the auspices of a mistaken pathology, in its present acceptation is connected with no theory, whilst it clearly and correctly distinguishes the disease.

There are many other portions of the works before us we had intended to notice; as the nature and affinities of relapsing fever; the necessity assumed by some writers, arnongst whom is Dr. Anderson, of erecting the gastric type into a separate group, and the convexion of that type with enteric fever; the opinion held by Dr. Murchison of the close relationship, if not identity, of typhus and true plague; but these we must content ourselves with suggesting for the consideration of our readers. The whole field of continued fever is so vast, that it should be the purpose of the reviewer rather to indicate its features than vainly to endeavour to exhaust its soil. 